\title{
QUALITY BENCHMARKING IN BUSINESS PERFORMANCE USING SURVEYING TECHNIQUE - REVIEW
}

\author{
Sivasankaran. $\mathrm{P}^{1 \rrbracket}$, Radjaram. $\mathrm{B}^{2}$ \\ ${ }^{1}$ Associate Professor, Department of Mechanical Engineering, Manakula Vinayagar Institute of Technology, \\ Pondicherry - 605 107, India \\ 2 Professor \& Head, Department of Mechanical Engineering, Manakula Vinayagar Institute of Technology, \\ Pondicherry - 605 107, India
}

Received 31 July 2021

Accepted 11 August2021

Published 31 August 2021

\section{CorrespondingAuthor}

Sivasankaran. P,

sivasankaranmech@mvit.edu.in

DOI

10.29121/granthaalayah.v9.i8.2021. 4156

Funding: This research received no specific grant from any funding agency in the public, commercial, or not-for-profit sectors.

Copyright: (C) 2021 The Author(s). This is an open access article distributed under the terms of the Creative Commons Attribution License, which permits unrestricted use, distribution, and reproduction in any medium, provided the original author and source are credited.

\section{ABSTRACT}

In today's scenario every business organization will try to establish their own objectives/Goals for successful execution in every stage of business performance management system. Benchmarking plays a major role in today's highly competitive work culture in order to compare the actual performance or output against the known standards. Using benchmarking tool, we can assess the performance of business process by measuring the quality of resources, cost of resources, Market share assessment and customer satisfaction level etc are some of the factors which are strongly considered for evaluation. With the help of this tool, we can find out the strength and weakness of the organization. In this paper attempt has been made to conduct survey analysis based on literature review information. The study is focused on the performance of engineering educational institutions in India with strong vision and mission statements. Hence a detailed survey form is designed using Google form applications with all parameters.

Keywords: Benchmarking, Business Performance Management, Survey Through Google Form

\section{INTRODUCTION}

Benchmarking is the process of comparing the cost, time, Quantity and quality of specific method to be improved. As per recent scenario customers demand for high quality, Increased service satisfaction through Benchmarking by means of comparison of other organization who are best in service and other aspects. Benchmarking is said to be the competitive tool used for measuring the inline activities of companies with against other organization to improve the objectives of organization.

\subsection{THE GOALS OF BENCHMARKING PROCESS}

The following are the goals of benchmarking process as listed below:

1) Validation of clear objectives, fixed targets and applications.

2) To strengthen the corporate culture.

3) Determination of best practices to achieve the objectives.

4) Implementing best practices within the company.

5) Providing motivation in teams and encourage the employee empowerment 
These are the above goals framed for quality benchmarking by the business organization. Benchmarking process has become an important role in all organization nowadays in order to have better comparison for efficient functioning of organization. In the benchmarking process two companies' information are taken into detailed consideration in order to gain competitive advantage in business operations. But some people may think that benchmarking process will have some critics among various peoples. Benchmarking will not have discrimination thinking instead it will provide better solution for possible improvement. Through comparison only we can know whether our business excels in current direction are not. Benchmarking mainly cares for customer satisfaction since organization is responsible for producing good product and services to the customer. So Benchmarking is the tool helps to measure the both good and bad aspects occurring within in the organization. Change management will increase the motivation of employees within the organization in order to achieve the goals. Benchmarking Process in organization will strongly influence the performance of one organization with respect to the other organization in terms of profit, Technological resources, skillful employees etc. Through benchmarking organization can able to implement best practices for better coordination of resources in well planned manner. The performance of the organization can be evaluated continually till the organization attains the success. Benchmarking can be carried out with respect to processes like strategic planning, Decision Processes, Manufacturing systems, Employee performance etc. Generally benchmarking is of two categories namely internal and external benchmarking respectively. Internal benchmarking means comparing the performance of two business units within the same group. Whereas external benchmarking comparing the performance of two different firms.

\section{LITERATURE REVIEW}

In this section the following articles describes the detailed review of benchmarking tool in various applications as listed below:

1) Sharfuddin Rashed et al. (2018) In this article authors have strongly focused on the importance of benchmarking tool utilized within the organization. Benchmarking is a way or direction for the organization which provides guidance to implement the best practices or ideas in the organization. In this work the authors have focused the existing work of benchmarking process in the manufacturing industries of Bangladesh. Also, some existing literatures and sreal-life examples of benchmarking are used for further study. Hence authors have given strong recommendation and proper direction for successful implementation of benchmarking.

2) Ayșenur Erdil et al. (2018) In this proposed work authors have focused the importance of benchmarking tool to increase the efforts to change and to remain permanent in the market for long period. Every organization need to be profit oriented in order to identify the possibilities of change and to provide the proper procedure or mechanism for change. Benchmarking helps to access, learn information for better improvement instead of storing information. Moreover, benchmarking tries to improve the weakness by enabling the best opportunity in the possible level. In this article authors have addressed two dual strategies namely 1 . Benchmarking 2. TQM. Also, in this study based on sample case studies 
and examples shows that how companies are using the benchmarking method for doing comparison process.

3) Savanam Chandra Sekhar (2010) Author clearly state that benchmarking is a technique used for assessing the firm performance with respect to the other existing standard firm. It is used to find the best possible practices for possible execution of objectives with all cooperation from various employees within the organization. The existing article mainly highlights the essential need of benchmarking to improve the company's own resources, performance indicators and quality improvement within the organizations. Benchmarking provides useful information for organizations with competitive advantages.

4) Maire Jean Luc et al. (2016) Benchmarking is one of the most effective tools used for performance improvement process of organization. The first challenge measured in this process is defining the best practices of organization based on the goals of organization. The second challenge is nothing but identifying the use of best practices in the given practical situation. In this work BPS method (Best Practice Specification) is one of the benchmarking tools used to evaluate the firm performance.

5) Houssein Elaswad et al. (2015) This work extremely describes about the use and functions of benchmarking operations in the organizations for improving the firm's assets and performance in terms of quality service by enriching the customer satisfaction by delivering valuable products and services to the customer. This research article explains about the functions of benchmarking process used in medium sized manufacturing unit. The following data gathered by the researchers through surveying from literatures are listed below: 1. Concept of benchmarking - Overview, 2. Efficiency and 3. Performance Production in Manufacturing unit. The literature review reveals that management skills, degree of skilled labor and capital investment are the various inputs required for successful benchmarking within the organization.

6) Dattakumar et al. (2003) Based on the vast literature review it clearly reveals that most of the organization focused on benchmarking tool to assess the potential strengths and weakness of the organization. From the past literature review it is noted that vast number of articles are based on benchmarking process that clearly reflects the interest in the research. In this article authors have reviewed benchmarking tool in such a way that would help academicians, research scholars and practitioners to have a sharp focus on Growth, Development and Application level.

7) Bala Krishnamoorthy et al. (2014) In specific competiveness is the order of the day and benchmarking is the tool used to help the company's performance in consistent performance. This study describes the detailed review of literature about benchmarking process that will facilitate the researchers, academicians and Managerial personals for enriching the best quality practices by using benchmarking process.

8) Rajagopalan Jayaraman (2017) In this article author has mentioned two different techniques /Tools namely Business Excellence Model \& TQM these are the two techniques strongly suggested throughout the entire work. In this literature two main Indian namely Tata steels and L\&T are studied thoroughly using these tools in terms of Leadership, Strategy, Customer focus, Knowledge and Information Management, Human 
Resources and Processes etc. In this research author used Qualitative methodology to measure the efficiency of Business Excellence and TQM Models.

9) Moise Ioan Achim et al. (2009) Due to the growth of high competition, High demands for accountability and higher volumes of available information are forced to change the methods/procedures of higher education institutes to operate nowadays. In Today's fast-growing environment, the role of higher education institutes plays a vital role in quality enriching of teaching and learning as well as research activities etc. Among several management tools and techniques benchmarking is said to be one of the most useful, easily understood tool for management practitioners within the educational institutions. In this work the aim is to understand the importance of Benchmarking in Higher Educational Institutes.

10) Bikram Jit Singh et al. (2015) The aim of proposed research article clearly explains the student academic excellence through by means of Internal Assessment Criteria that indirectly improves the outcomes of academics Through proper evaluation by conducting exams. The entire work is fully focused on Indian Engineering Educational Institutes especially private institutes including infrastructure, Facilities, type of education provided and exposure to real life problems etc., are the factors taken by the authors to study the quality of higher learning institutes in Indian Environment.

From the above literatures it is observed that using benchmarking technique several authors have contributed their ideas in both industrial organization and Educational Institutions. But in this paper attempt has been made to focus on educational institutions how benchmarking can be executed in educational setup.

\section{METHODOLOGY}

\section{Case Study:}

In this section the benchmarking operations as well as processes are described in detail with the help of case study by taking two educational higher learning engineering institutes say Institution X \& Institution Y respectively. Let us consider that institution $\mathrm{X}$ is the standard institution stands as benchmark or reference institution for neighboring institution say Y.

Following are the details of reference/Bench mark Institution $\mathrm{X}$ as listed below:

\section{Details of Institution X:}

Table 1 Institutional Details

\begin{tabular}{|ccc|}
\hline S.No & List Of Items & Scores Awarded (out of 10) \\
\hline 1. & Institute Accreditation & 09 \\
\hline 2. & Organizational objectives & 08 \\
\hline 3. & Teaching / Learning Objectives as per OBE model & 08 \\
\hline 4. & IQAC conductance in every semester & 09 \\
\hline 5. & Students' satisfaction level in classroom & 09 \\
\hline 6. & Lab facilities as per high learning standards & 08 \\
\hline 7. & Achievement of graduate attributes & 09 \\
\hline
\end{tabular}




$\begin{array}{cc}\text { 8. } & \text { Research / Startup/Incubation } \\ 9 . & 09 \\ \text { Overall satisfaction } & 78 \\ \text { Total } & 8.66\end{array}$

From Table 1. The above data are based on the details of Institution X which stands for Quality, Continuous improvement and lifelong learning. In this case study through survey mechanism the performance of Institution $Y$ has to be compared with Institution X.

Details of Institution Y: The following are the details that are assessed by comparing with Institution $\mathrm{X}$ through surveying techniques from multiple respondents. The Following are the factors listed below ranging from Institute accreditation details, Organizational mission/Vision, Teaching /Learning Objectives, IQAC activities, students' satisfaction level, Lab facilities, Achievement of Graduate outcomes, Research /Startup/Incubation \& Overall Satisfaction. These are the above factors listed for benchmarking the similar quality with respect to standard Institution.

The following are the statistical details related to institution Y collected through Google survey link from 10 respondents including students, Faculties \& Industry Personal as listed below from Figure 1, Figure 2, Figure 3, Figure 4, Figure 5, Figure 6, Figure 7, Figure 8, Figure 9 respectively. The detailed statistical comparison is carried out to benchmark the quality of Institution $\mathrm{Y}$ with respect to Institution $\mathrm{X}$. The following are the statistical information represented in graphs under each functional parameter. The details about the graphs are explained in detail in Results and Discussion section.

1. Whether the Institute is accredited by NBA/ NAAC

8 responses

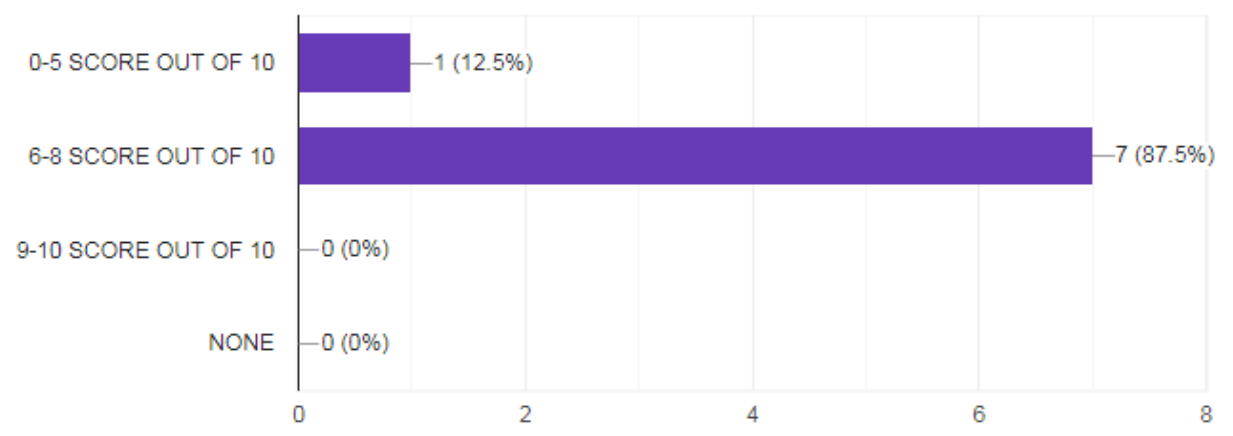

Figure 1 Represents the statistical information about the Institution accreditation process. From the graph it is observed that $87.5 \%$ of the respondents have the given the scale rating in the range of $6-8$ out of 10 . The remaining $12.5 \%$ respondents gave scale rating $0-5$ out of 10 
2. Whether Organizational objectives are properly bench marked by comparing with other standard Organization.

8 responses

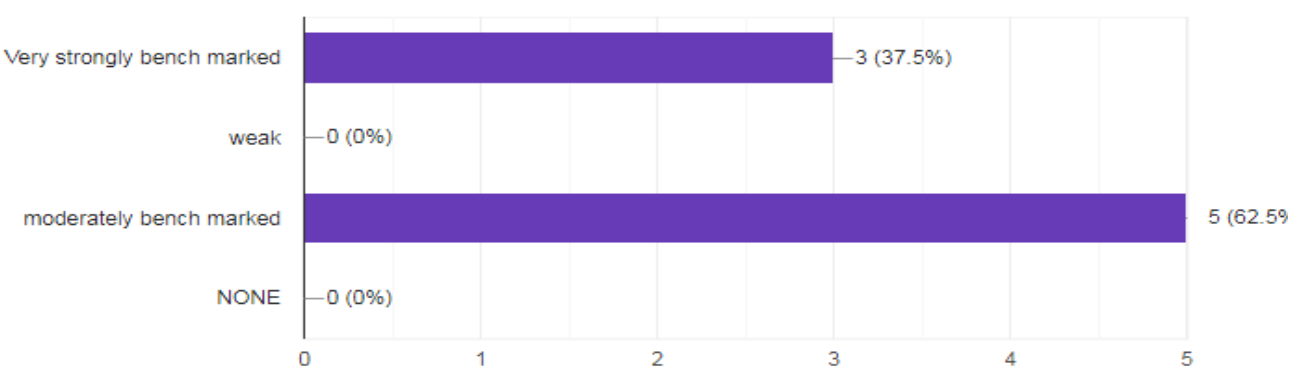

Figure 2 Represents the statistical illustration about the benchmarking of organizational objectives. About $37.5 \%$ respondents gave the comments as strongly benchmarked remaining $62.5 \%$ respondents gave the comments as moderately benchmarked.

3.Whether Teaching /Learning objectives are properly carried out as per outcome based education model

8 responses

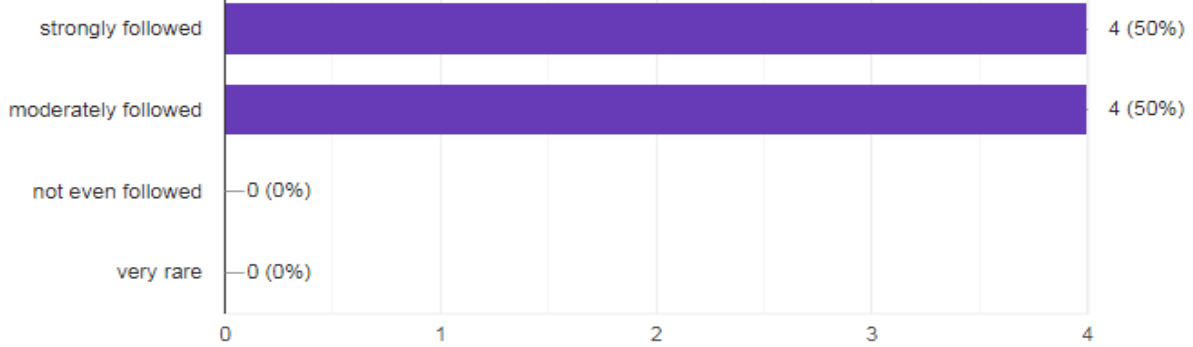

Figure 3 Represents the information about the teaching /learning outcomes. About $50 \%$ of the respondents gave the comments as strongly benchmarked and remaining $50 \%$ of the respondents gave the comments as moderately benchmarked.

4. Whether IQAC(Internal Quality Assurance cell) activities are carried out regularly on every semester in the Institution.

8 responses

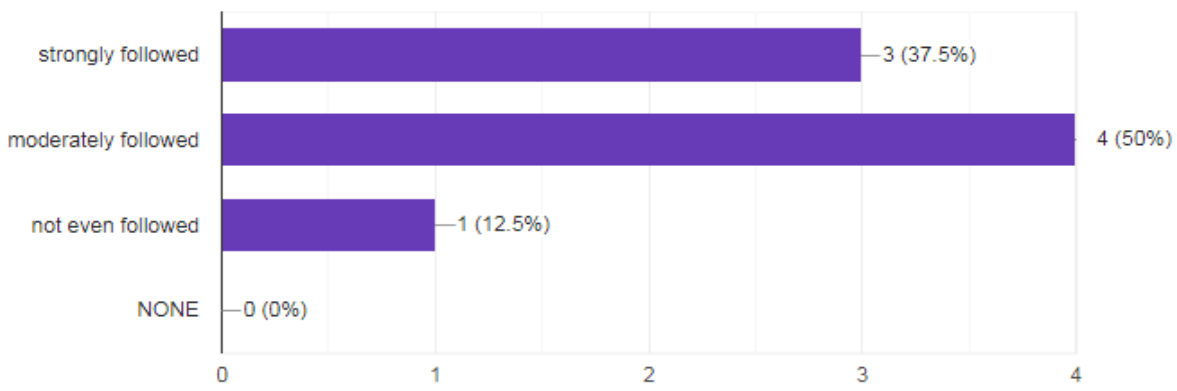

Figure 4 Represents the data about the IQAC activities (Internal Quality Assurance Cell) based on the graph following are the inferences $37.5 \%$ of the respondents gave the comments as strongly followed, $50 \%$ of the respondents gave the comments as moderately followed and remaining $12.5 \%$ of the respondents gave the comments as not even followed 
5. Whether students satisfaction level in classroom activities are properly carried out

8 responses

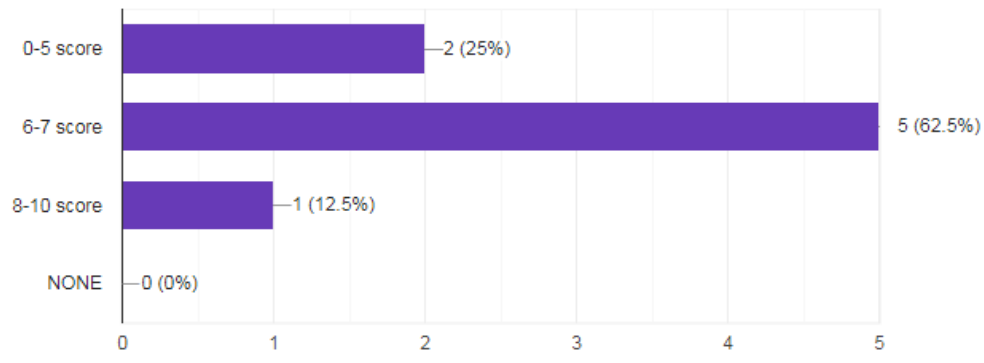

Figure 5 Represents the data about the student's satisfaction level in classroom activities nearly $12.5 \%$ of the respondents gave the scale rating as $8-10$ out of 10 , next $62.5 \%$ of the respondents gave the scale rating as 6 to 7 out of 10 and $25 \%$ of the respondents gave the scale rating as 0-5 out of 10 .

6.Whether all the lab facilities as well other facilities or support provided by the higher learning institutions are in which level

8 responses

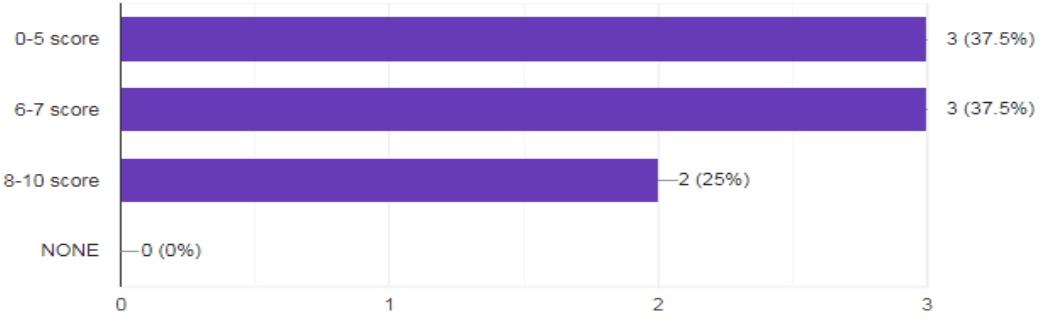

Figure 6 Represents the data about the lab facilities available in higher learning institutes nearly 25 $\%$ of the respondents gave the comments as $8-10$ out of 10 , next $37.5 \%$ of the respondents gave the scale rating as 6-7 out of 10 \& remaining $37.5 \%$ of the respondents gave the scale rating as $0-5$ out of 10

7.whether graduate attributes are properly measured in terms of employ ability/ life long learning .

8 responses

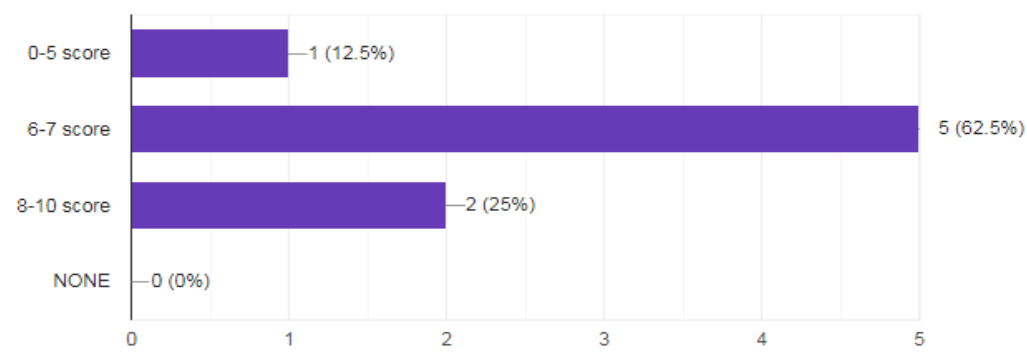

Figure 7 Represents the data about the graduate attributes in terms of lifelong learning nearly 25 $\%$ of the respondents gave the comments as $8-10$ out of 10 , next $62.5 \%$ gave the comments as 6-7 scale rating out of 10 and remaining $12.5 \%$ of the respondents gave the rating as $0-5$ out of 10 
8. whether Research/Startups/Incubation are given importance in the institution.

8 responses

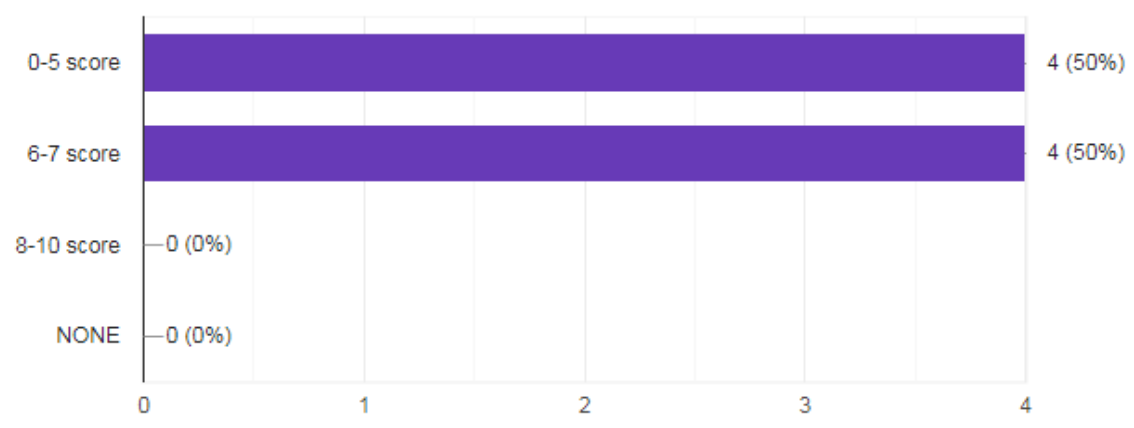

Figure 8 Represents the information about the startup / Research facilities in higher learning institutes nearly $50 \%$ of the respondents gave the scale rating as 6- 7 out of 10 and remaining 50 $\%$ of the respondents gave the scale rating as $0-5$ out of 10 .

9.What is the overall satisfaction from the Institute based on the services provided?

8 responses

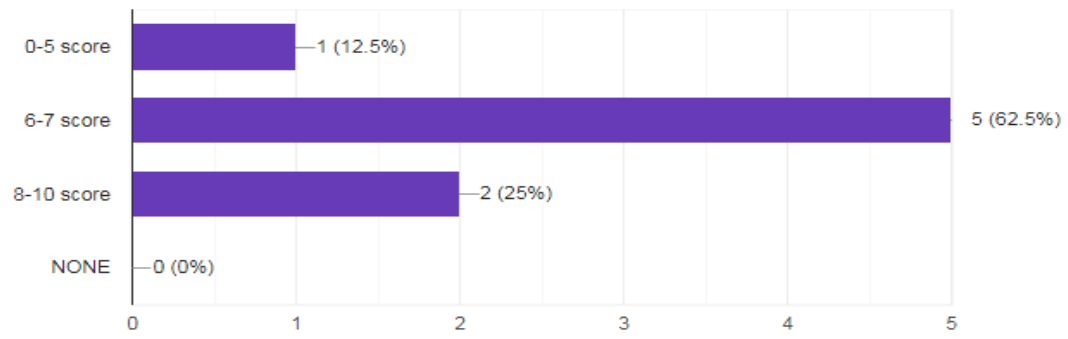

Figure 9 Represents the information about the overall satisfaction from the institutes nearly $25 \%$ of the respondents gave the scale rating as $8-10$ out of 10 , next $62.5 \%$ of the respondents gave the scale rating as 6-7 out of 10 and $12.5 \%$ of the respondents gave the scale rating as $0-5$ out of 10 .

\section{RESULTS AND DISCUSSIONS}

In this section detailed summary is presented based on the above graphical illustrations from Figure 1, Figure 2, Figure 3, Figure 4, Figure 5, Figure 6, Figure 7, Figure 8, Figure 9 respectively. The following are the main factors to be focused strongly based on the cumulative statistical information as listed below:

1) Organizational Objectives

2) Teaching / Learning outcomes

3) IAQC activity

4) Students' satisfaction level

5) Lab facilities

6) Graduate attributes

7) Research facilities/startup

8) Overall institute performance 
These are the above factors to be focused more strongly in order to have strong benchmark standards in improving the quality of technical higher learning institutes. To have a successful vision every organization must strive hard towards the common goal.

\section{CONCLUSION}

Bench marking is said to be the tool used for comparing the both strength and weakness of the organization. The purpose of bench marking process is to observe the weakness of the organization thereby transforming the weakness into positive outcomes for enhancing the productivity of the organization. Successful bench marking requires 360-degree assessment about the several resources for productivity upliftment. Bench marking requires through careful analysis to find out the impact of employee skills, professional attitude and culture etc. In this paper attempt has been made to propose a case study in which two technical higher learning technical institutions are considered the pros and cons of institution Y are benchmarked with respect to Institution X. Based on the benchmarking process the above factors are identified for possible improvement as mentioned in the previous section. For a successful higher learning Technical Institution all the factors like academics, Research, student's empowerment and other extra items are focused with high importance. Hence benchmarking process is said to be comparative estimation of organization with reference to the standard organization.

\section{REFERENCES}

Ayşenur Erdil, Hikmet Erbiyık (2018), The Importance of Benchmarking for the Management of the Firm: Evaluating the relation between Total Quality Management and Benchmarking , 3rd World Conference on Technology ,Innovation and Entrepreneurship , Procedia Computer Science 158 ,PP: 705-714. Retrived from https://doi.org/10.1016/j.procs.2019.09.106

Bala Krishnamoorthy \& Christine D’Lima (2014), Benchmarking as a Measure of Competitiveness, International Journal of Process Management and Technology, PP : $\quad 1$ - $18 . \quad$ Retrived from https://doi.org/10.1504/IJPMB.2014.063240

Bikram Jit Singh and Rakesh Joshi (2015), Benchmarking academics through sustainable assessment criteria: an Indian case study, Benchmarking : International Journal , Vol: 22 , Issue: 3 , PP: 505 -536 . Retrived from https://doi.org/10.1108/BIJ-01-2013-0006

Dattakumar \& Jagadessh (2003), A Review of Literature on Benchmarking, Benchmarking: International Journal, Vol: 10 ,Issue :3, PP: 176-209 . Retrived from https://doi.org/10.1108/14635770310477744

Houssein Elaswad, Shahidul Islam, Syed Tarmizi, Abdulha Yassin, Man Djun Lee, and Ting C.H (2015), Benchmarking of Growth Manufacturing SMES : A Review, Sci.Int.(Lahore),27(3), PP: 2039-2048. Retrived from https://d1wqtxts1xzle7.cloudfront.net/37856795/Houssein_Elaswad1-banchmarking_SMEs.--MALAYSIA.pdf?1433777839=\&response-contentdisposition=inline\%3B+filename\%3DBENCHMARKING_OF_GROWTH_MAN UFACTURING_SME.pdf\&Expires=1630131918\&Signature=CWM2XDIGDPo 
dIBNWqdJe7rrhQgEhaCCAK0jKy7iyLVxT33yCWsTBExGmJ9EN2Vliha5EW 6hdjUNci3by33R4Wje-

eZYbS7eVRGIDoxU71CmDaH0kViae Vis1siYGH7KyLSFvhZnDxEdRLrUim $\sim$ wVdAZL7WRgS-

bmf44lB3pyaYB1b0VlKJ4nFTID5quhKyTK0Luju30Rney3H9kFONJ5I6Wn

BxGLfTMfOjelJcC6u6PBxKOd7SOQI6U1fqrvRoCQygh-q5GPB5mvsxYClCBn8rlXmlkfM-

edZ8XwgxwpHq3qMXccgkMA6uTAHSdV1MwImIr98j01Fs7da4mPd0HQ \&Key-Pair-Id=APKAJLOHF5GGSLRBV4ZA

Maire Jean Luc, Bronet Vincent \& Pillet Maurice (2016), A Typology of Best Practices for Benchmarking process, Benchmarking for Quality Management \& Technology, PP: 1-14. Prom https://doi.org/10.1108/14635770510582907

Md. Sharfuddin Rashed \& Nesha Ashraf Un (2018), Implementation of Benchmarking Concepts in Manufacturing Industry of Bangladesh, Global Journal of Management and Business Research: A Administration and Management, Volume 18 Issue 4,PP: 1-10.

Moise Ioan Achim, Lucia Căbulea , Maria Popa \& Silvia - Stefania Mihalache (2009), On The Role Of Benchmarking In The Higher Education Quality Assessment , Annales Universitatis Apulensis Series Oeconomica, 11(2), pp: 1-8. Retrived from https://doi.org/10.29302/oeconomica.2009.11.2.27

Rajagopalan Jayaraman (2017), An Empirical Study of Continuous Improvement Practices Using BE/TQM Frameworks - Case Studies from Indian Industry, Amity Journal of Operation Management, Vol: 2(1) , PP: 28-50. Retrived from https://amity.edu/UserFiles/admaa/cd9ebPaper\%202.pdf

Savanam Chandra Sekhar (2010), Benchmarking, African Journal of Business Management, Vol : 4, PP :882-885. Retrived from https://www.internationalscholarsjournals.com/articles/benchmarking.p df 